\title{
Büyük Menderes Grabeninde Cisim Dalgalarının Frekans Bağımlı Soğrulma Karakterinin Belirlenmesi
}

\author{
Alper Demirci ${ }^{1, *}$, Tolga Bekler $^{1, * *}$ \\ ${ }^{1}$ Çanakkale Onsekiz Mart Üniversitesi, Mühendislik Fakültesi, Jeofizik Mühendisliği Bölümü, 17100, Çanakkale. \\ *ORCID: 0000-0002-8710-6232, ** ORCID: 0000-0002-9475-8626

\section{Özet}

Bu çalışmada, Büyük Menderes grabeninin kuzey sınırı boyunca gelişen fay toplulukları ve bunların Ege Denizi'ne doğru uzantıları boyunca oluşmuş 66 deprem verisi kullanılarak bölgeye ait soğrulma karakteristikleri ortaya konmaktadır. Çalışmada, $P$ ve $S$ dalgalarının soğrulma fonksiyonları, koda normalizasyon tekniği ile hesaplanmıştır. Çalışma kapsamında elde edilen sonuçlar, bölgede veya yakın civarında gelecekte olması muhtemel büyük depremlerin daha doğru bir şekilde modellenebilmesi ve sismik risk çalı̧̧malarının da daha güvenilir sonuçlar elde edilmesi için gerekli olan temel parametrelerden biri olan sönüm ilişkilerini ortaya koymaktadır. Buna göre, $S$ ve $P$ sismik fazlart için sirastyla, $Q_{s}=79.2 \pm 14.6 f^{0.9 \pm 0.07}$ ve $Q_{p}=32.9 \pm 13.7 f^{1.05 \pm 0.16}$ fonksiyonlarl elde edilmiştir. Ayrıca $1 \mathrm{~Hz}$ ' den büyük frekanslarda $Q_{S} / Q_{P}$ oranı ortalama 1.75 olarak hesaplanmıştır. Elde edilen sonuçlara göre düşük $Q p$ ve $Q s$ değerleri ve bunların oranları $\left(Q_{S} / Q_{P}\right)$ saçılma etkisinin fazlalığını işaret etmekte ve bunun da çalışma alanındaki özellikle üst kabuktaki yoğun yanal heterojenitenin bir sonucu olduğu şeklinde yorumlanabilmektedir.

\section{Anahtar Sözcükler}

Soğrulma, Büyük Menderes Grabeni, Deprem, P Dalgası, S Dalgası

\section{Frequency Dependent Attenuation Characteristics of Body Waves in Büyük Menderes Graben}

\begin{abstract}
In this study, 66 earthquake data, along the faults of northern boundary of the Büyük Menderes Graben and their continuations in the Aegean Sea, were used to reveal the body wave attenuation characterization of the region. The attenuation functions of the P and $S$ waves are calculated by the coda normalization technique. The results obtained in this study reveal attenuation relations, which are one of the basic parameters required to modelling large earthquakes in the region and to obtain more reliable results from necessary seismic risk studies. The power-law functions were obtained for the $S$ and $P$ seismic phases as $Q_{s}=79.2 \pm 14.6 f 0.9 \pm 0.07$ and $Q_{p}=32.9 \pm 13.7 f^{1.05 \pm 0.16}$ respectively. Also the $Q S / Q P$ ratio is calculated as $\sim 1.75$. for the frequencies greater than $1 \mathrm{~Hz}$. According to the results, the low $Q p$ and $Q s$ values and their ratios $(Q S / Q P)$ indicate the abundance of scattering effect, which can be interpreted as a result of intense lateral heterogeneity in the upper crust.
\end{abstract}

Keywords

Attenuation, Büyük Menderes Graben, Earthquake, P Wave, S Wave

\section{Giriş}

Bir deprem kaydı bütünüyle depreme neden olan sismik kaynağın odağına ait parametrelerini (odak derinliği, kaynak mekanizması, faylanma karakteristikleri...) ve o kaydın alındığı sismometre düzeneğine ait kaydı daha anlaşılabilir bir seviyeye getirmek için belirlenmiş alet etkisi parametrelerini içermektedir. Bu iki etki (kaynak ve alet) yanında, sismik dalgaların kaynaktan kayıtçıya ulaşana kadar içerisinde ilerlediği ve deprem bölgesine ait en önemli bilgileri içinde barındıran heterojen ortam ise ilgili deprem kaydının temel bileşenlerinden birini oluşturmaktadır. Sismologların özellikle yaklaşık son yarım yüzyılda, çalışma konularının temelini bu etkilerin birbirlerinden veya ham deprem verisinden ayırılması üzerine yaptıkları görülmektedir.

Özellikle ortam etkisi, kendi içinde incelendiğinde geometrik yayınım, saçılma, soğrulma ve sı̆̆ zemin etkisi bileşenlerini içinde barındırmaktadır. Bu etkilerin en doğruya yakın bir şekilde temsil edilmesi kaynağa ait parametrelerin belirlenmesindeki muhtemel hata oranı ile doğrudan ilişkilidir. Dolayısıyla, sismoloji alanında yapılan hemen hemen her çalışmada olasılıksal yaklaşımlardan daha çok ortama ait özelliklerin en güvenilir ve doğru şekilde bilinmesi tercih edilmektedir. 
Ortama ait soğrulma özelliği, kabuğun plastisite özelliği ve heterojenite miktarı veya her ikisinin de neden olduğu sismik dalga genliğindeki azalma miktarı ile ifade edilmektedir. Bu ifade genellikle bir birimi olmayan Q parametresi ile ölçeklendirilmektedir. Kalite faktörü olarak isimlendirilen bu parametre ilgili sismik dalga yayılımına ait ortam özelliklerini barındırması bakımından kendine özgü bir büyüklüğe sahiptir.

Aki (1980), S dalgası spektral genliklerinin koda spektral genliklerine normalize edilmesi işlemi ile bu dalga fazına ait soğrulma kalite faktörünün (Qs) $1.5-18 \mathrm{~Hz}$ arası frekans bandında frekans bağımlılı̆̆ını ortaya çıkarmıştır. Sato ve Matsumura (1980), yüzey dalgası ve sığ zemin soğrulma karakterine olan etkisinden kaçınmak için derin kuyu gözlemleri ile normalizasyon işlemini gerçekleştirmişler ve Aki (1980) ile uyumlu sonuçlar elde etmişlerdir. Bu durum, kullanılan yöntemin doğası gereği, normalizasyon işlemi sırasında alet, zemin ve kaynak etkilerinin doğal olarak giderilebildiğinin bir göstergesi olmuştur. Bu bulgulardan sonra, teknoloji alanındaki hızlı gelişmelere paralel olarak ve yüksek hızlı çözüm kabiliyetine sahip bilgisayar sistemlerinin ortaya çıkması ile bu çalışmalar, farklı tektonik karakterlere sahip alanlarda sinyal/gürültü oranı yüksek veri kullanımı ile günümüze kadar artarak devam etmektedir. Yerel veya küresel ölçekte gerçekleştirilen bu tür çalışmalarının artması, bu çalışmaların birbirleri ile karşılaştırılması ve içinde bulundukları tektonik özellikler itibariyle de karşılaştırılmalı olarak yorum yapılabilmesine olanak sağlamaktadır.

Bu çalışma kapsamında da, Batı Anadolu'da genişlemeli tektonik rejimin sonucu olarak oluşan graben sistemlerinden biri olan Büyük Menderes grabenini sınırlayan fay sistemleri boyunca gelişen deprem verilerine koda normalizasyon tekniği kullanılarak bu bölgenin frekans bağımlı soğrulma karakterinin ortaya çıkarılması amaçlanmaktadır. Aynı zamanda, bölge ve yakın civarındaki yerleşim alanlarının çokluğu ve nüfus dağılımı açısından özellikle sismik risk anlamında, bölgenin ileride maruz kalabileceği sismik olayların daha doğru modellenebilmesi için bu çalışma bir altlık olma özelliği taşımaktadır.

\section{2. Çalışma Alanı ve Tektonik Özellikleri}

Çalışma alanı, dünyada sismik açıdan en aktif ve en çok deprem üreten bölgelerden biri olan Batı Anadolu'da yer almaktadır. Batı-Güney Batı Anadolu, Geç Miyosen'den günümüze (Neotektonik dönemde), birden çok tektonik rejimin etkisi altında kalmıştır. Batı Anadolu'da, Geç Miyosen-Geç Pliyosen aralığında, KD-GB ve DKD-BGB doğrultusunda normal faylar ve ilişkili havzaların şekillendikleri düşünülmektedir (Arpat ve Bingöl 1969; Şengör vd. 1985; Seyitoğlu ve Scott 1991; Barka ve Reilinger 1997). Geç Pliyosen'de, KB-GD doğrultulu sıkışma rejimi altında, DKD-BGB ve BKB-DGD gidişli doğrultu atımlı deformasyon egemen iken, Geç Pliyosen sonrası (Kuvaterner) KKD-GGB doğrultulu açılma rejimi hakim olmuştur. Dolayısıyla, gelişen bu tektonik rejim değişikliği sonrası, önceki yapısal gidişleri kullanan, Ege Levhasını kesen, uzunlukları 100 km'yi geçmeyen ve DKD-BGB, BKB-DGD ile D-B doğrultularında uzanan normal faylar ile bunların önünde gelişen graben ve yarı-graben havzalarını görmek mümkündür (Şengör ve Yılmaz 1981; Şengör 1987; Hancock ve Barka 1987; Koçyiğit 2000). Bu yoğun tektonizma sayesinde bölge, dünyada sismik açıdan en aktif ve en çok deprem üreten bölgelerden biri haline gelmiştir (Reilinger vd. 1997; Jackson ve McKenzie 1988; Ambraseys 1988; Taymaz vd. 1991; Bozkurt 2001). Batı Anadolu'daki bu karmaşık tektonik yapının zaman ve nedenleri günümüze kadar farklı görüşleri de beraberinde getirmiştir. Fakat yapılan bütün bu çalışmaların ve elde edilen sonuçların ortak noktası günümüzde Batı Anadolu'da aktif bir genişleme rejimin hakim olmasıdır (Dewey ve Şengör 1979; Şengör vd. 1985; Görür vd. 1995; Seyitoğlu ve Scott 1991; McClusky vd. 2000; Koçyiğit vd. 1999; Bozkurt 2003).

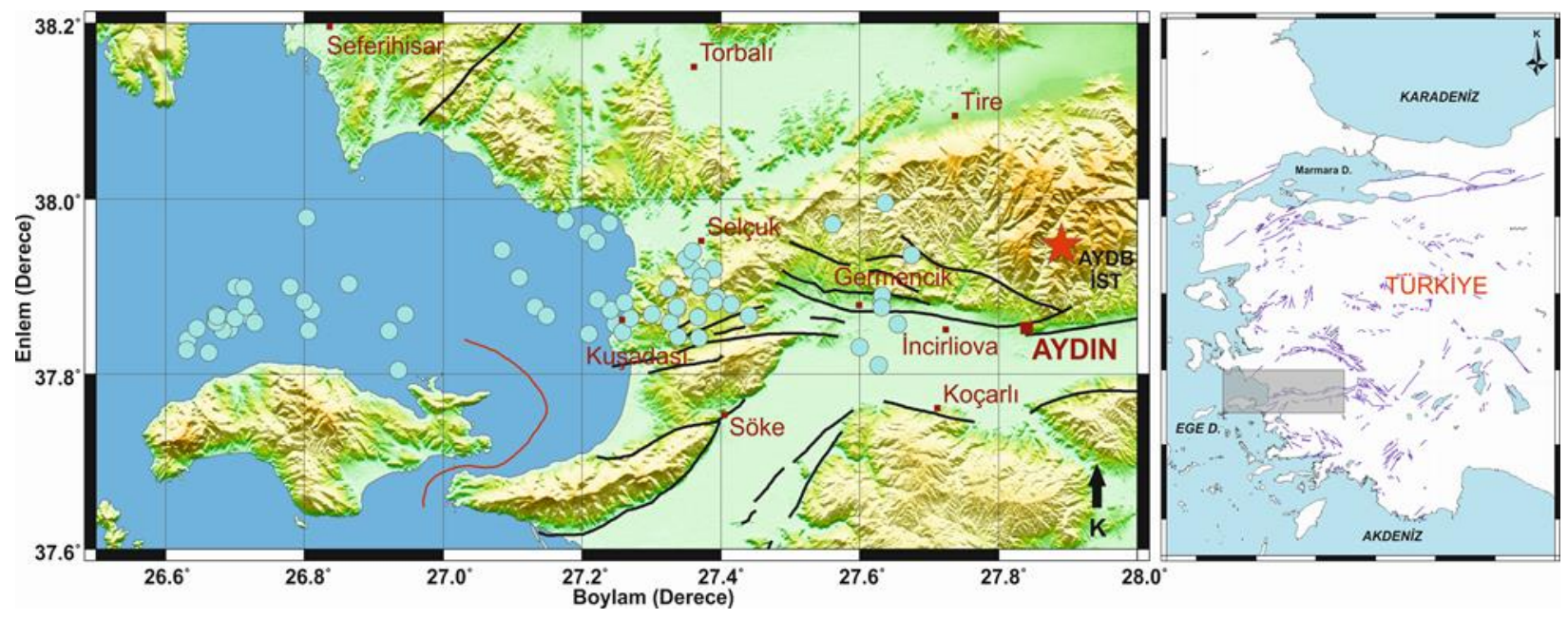

Şekil 1: Çalışma alanındaki aktif faylar (Emre vd. 2012) ve çalışmada kullanılan depremlerin dış odak dağılımları

Büyük Menderes Grabeni de bu aktif genişleme rejiminin en dikkat çeken ürünlerinden biridir. Denizli ili sınırları içerisinden başlayıp Ege Denizi'ne kadar devamlılık gösteren bu yapı içerisinde aletsel ve tarihsel dönemde önemli depremlere neden olan, graben yapısını Kuzey ve Güney'den sınırlayan önemli fay zonları bulunmaktadır. 
Grabenin güneye eğimli ana fayı Kuzey kenar boyunca gelişirken, graben yapısı Germencik ilçesi civarında iki bölüme ayrılmaktadır. Graben içerisinde meydana gelen depremler Aydın ili Batısında yoğunlaşmakta ve Ege Denizi içerisine kadar uzanan bir çizgisellik sunmaktadır. Özellikle yoğun yerleşim alanlarının bulunduğu bölgede, tarihsel dönemde oldukça yıkıcı etkileri olan depremler meydana gelmiştir (Guidobani vd. 1994; Ambraseys ve Finkel 1995; Altınok vd. 2011). 1645, 1654 ve 1702 depremleri Denizli-Aydın arasında gerçekleşirken 1899 yılında bölgeyi IX şiddetinde bir hasara maruz bırakan Menderes Vadisi Depremi meydana gelmiştir (Ambraseys ve Finkel 1995). Aletsel Dönemde yoğun sismik aktivite ile devam eden bu hareketlilik, bölgede sismik tehlike açısından büyük önem arz etmektedir. Bu çalışma kapsamında çalışma alanında, özellikle grabenin kuzey kenarını sınırlayan fay toplulukları ve bunların Ege Denizi içerisindeki uzantıları boyunca 2010 yılından sonra meydana gelen büyüklükleri 2.8 ile 4.7 arasında değişen 66 deprem verisi ele alınmıştır (Şekil 1).

\section{Yöntem ve Veri}

Frekans bağımlı soğrulma etkisini ortaya koymak amacıyla bu çalışmada kullanılan koda normalizasyonu yönteminin temelinde, geniş-band tek istasyon verisinin farklı frekans bandları aralığında filtrelenmiş ve her bir merkez frekans değerindeki sismik fazlara (S,P) ait spektral genliklerin, ilgili fazlara ait koda dalgası genliklerine normalize edilmesi işlemi bulunmaktadır (Şekil 2). Koda dalgaları, yer içindeki yoğun heterojenite nedeniyle oluşan saçılmış S dalgalarından oluşmaktadır (Aki 1969; Sato 1977). Dolayısıyla, Aki (1980), kaynak-alıcı uzaklığından bağımsız olarak oluşan koda dalgalarının başlangıç zamanı $\left(t_{C}\right)$ için, deprem oluş zamanından itibaren istasyona ulaşan $\mathrm{S}$ dalgası seyahat zamanının iki katından daha fazla bir gecikme ile olacağını ve bu dalgalarının spektral genliklerinin ise

$$
A_{C}\left(f, t_{C}\right)=S_{S, P}(f) P\left(f, t_{C}\right) G(f) I(f)
$$

eşitliğiyle ifade edilebileceğini ortaya koymuştur. Eşitlikte, f frekansı, $S_{S, P}(f)$ sismik dalga fazı kaynak spektral genliğini, $P\left(f, t_{C}\right)$ koda uyarım faktörünü, $G(f)$ zemin etkisi fonksiyonunu ve $I(f)$ ise alet etkisini içermektedir. Normalize işlemini gerçekleştirmek için, doğrudan S dalgası spektral genlikleri (Eşitlik 2) koda dalgası bileşenlerini içeren eşitlik (1)'e oranlanması gerekmektedir.

$$
A_{S, P}(f, r)=R_{\theta \varphi} S_{S, P}(f) r^{-\omega} \exp \left(-\frac{\pi f}{Q_{S, P}(f) V_{S, P}} r\right) G(f, \psi) I(f)
$$

Eşitlik 2'de ise $R_{\theta \varphi}$ kaynak yayınım modelini ifade ederken, $\omega$ geometrik yayınım bileşenini temsil etmektedir. Bununla birlikte, $Q_{S, P}(f)$ ilgili dalga fazına ait sönüm kalite faktörünü, $V_{S, P}$ ortamdaki oratalama $\mathrm{S}$ ve $\mathrm{P}$ dalga hızını ve $\psi$ işareti ise ilgili faz için geliş açısını göstermektedir.

$\frac{A_{S, P}(f, r)}{A_{C}\left(f, t_{C}\right)}=\frac{R_{\theta \varphi} S_{S, P}(f) r^{-\omega} \exp \left(-\frac{\pi f}{Q_{S, P}(f) V_{S, P}} r\right) G(f, \psi) I(f)}{S_{S, P}(f) P\left(f, t_{C}\right) G(f) I(f)}$

$\mathrm{Bu}$ işlem sonrası alet etkisi ve kaynağa ait spektral etkiler ortadan kalkmış olacaktır. Ayrıca, ilgili dalga fazına ait geliş açısı bileşeni $(\psi)$ için, birçok depremin dağılımı dikkate alındığında, farklı olayların farklı geliş açıları sergilemesi nedeniyle bu değerin ortalama bir değer ile temsil edilmesi, $G(f) / G(f, \psi)$ oranının da 1 olarak hesaplanarak yakın zemin etkisinin de doğal olarak giderilmesini sağlayacaktır. Aynı şekilde, kaynak yayınım modelini de $\left(R_{\theta \varphi}\right)$, farklı birçok kaynağın farklı kaynak etkilerinin ortalaması şeklinde düşünürsek, bu etkinin de minimuma indirgenmesi bu parametrenin görmezden gelinebileceğini açıklamaktadır. Son olarak, hiposantr uzaklığından bağımsız olan gecikme zamanına $\left(t_{C}\right)$ bağlı olan koda uyarım faktörünü de $\left(P\left(f, t_{C}\right)\right)$ bir sabit $(\operatorname{sbt}(f))$ olarak ele alırsak, tüm bu gerçekleşen varsayımlar 1şı̆̆ında sonuç olarak

$\left\{\ln \left[\frac{A_{S, P}(f, r) r^{\omega}}{A_{C}\left(f, t_{C}\right)}\right]\right\}_{\mathrm{r} \pm \Delta \mathrm{r}}=-\frac{\pi f}{Q_{S, P}(f) V_{S, P}} r+\operatorname{sbt}(f)$

bağıntısı elde edilmektedir (Yoshimoto vd. 1993). Çalışmada geometrik yayınım etkisi $r^{\omega}$, kaynak-alıcı arası uzaklığının, moho derinliğinin $\left(\mathrm{h}_{\mathrm{m}}\right)$ iki katından daha az olduğu durumlar için $r^{-1}$ olarak, fazla olduğu durumlar için $\frac{1}{\sqrt{r .2 h_{m}}}$ olarak hesaplamalara katılmıştır (Hermann ve Kijko 1983). Çalışmada bölge için ortalama moho derinliği $\left(\mathrm{h}_{\mathrm{m}}\right) 30$ km olarak seçilmiştir (Özer vd. 2017). 


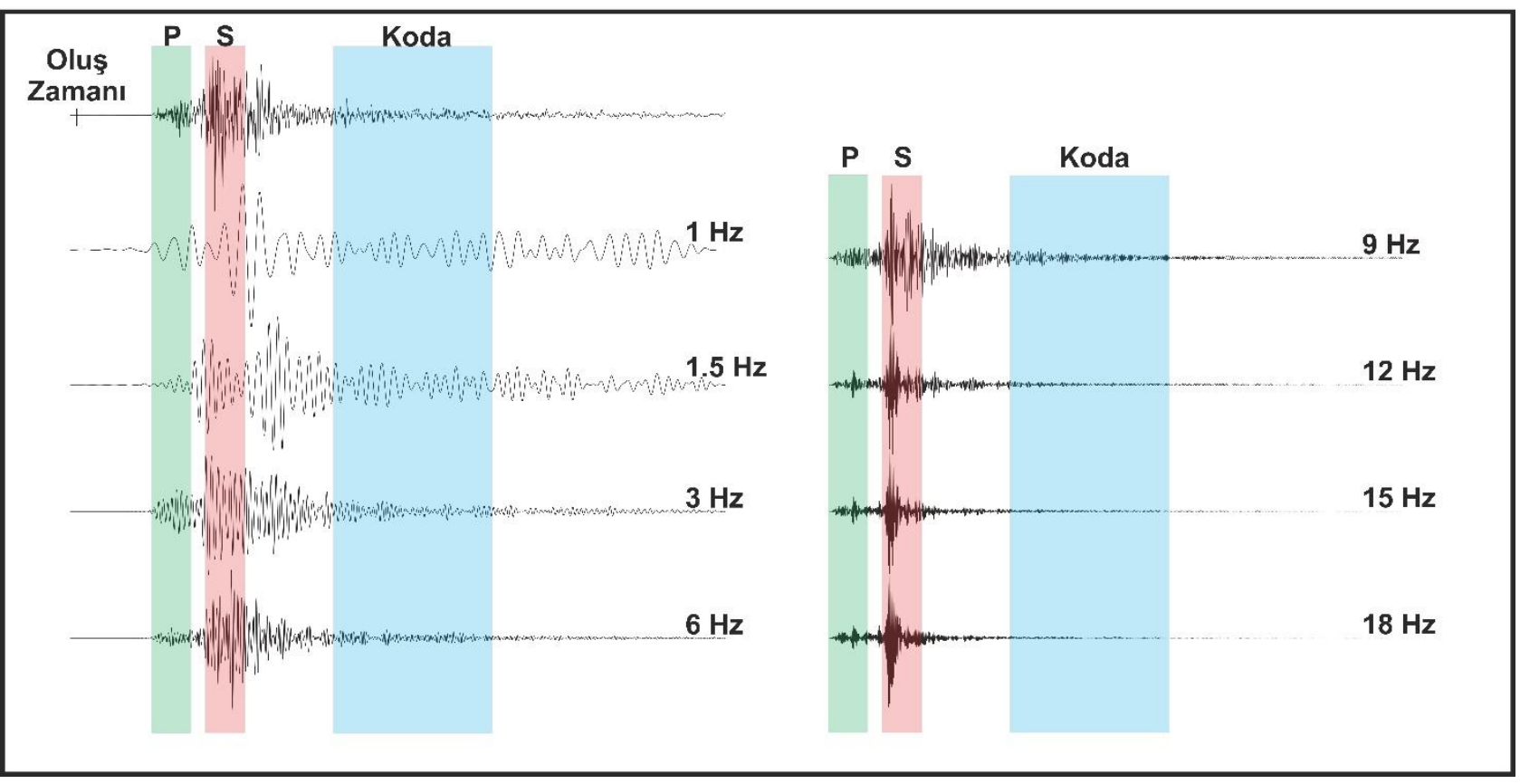

Şekil 2: Farklı frekans değerlerinde filtrelenmiş örnek veri ve seçilen $P, S$ ve koda zaman pencereleri

Bir sonraki aşamada ise, farklı kaynak-alıcı uzaklıklarına sahip birçok depremin, S ve P dalgası spektral genlikleri karekök ortalamaları (RMS) koda dalgası spektral genliği karekök ortalamasına normalize edilmesi işlemi gerçekleştirilmektedir. Bu normalizasyon işlemi sonucunda ulaşılan değerler, kaynak-alıcı uzaklığına bağlı olarak grafiklenmektedir. Elde edilen grafiklerde artan uzaklıkla bu değerlerin düşüş eğiliminde olduğu gözlenmektedir. Bu düşüş eğilimi en küçük kareler tekniği kullanılarak doğrusal regresyon işlemi ile anlamlı bir hale gelmektedir. Doğrusal regresyon işlemi sonucunda elde edilen eğim değeri, ilgili merkez frekansı için geçerli olan sönüm kalite faktörünü ortaya çıkarmakta kullanılmaktadır. Her faz için (P ve S) 1, 1.5, 3, 6, 9, 12, 15 ve 18 Hz'lik merkez frekanslar için elde edilen sönüm kalite faktörlerinin (Q), artan frekans değerleriyle olan değişimleri sönüm kalite faktörünün frekans bağımlılığın bir göstergesi olmaktadır. Bu frekans bağımlılığı güncel literatürde üstel regresyon analizi ile elde edilen fonksiyonlar ile gösterilmektedir.

Bu çalışmada, büyüklükleri 2.8 ile 4.7 arasında değişen 66 adet deprem için 198 dalga formu incelenmiş ve gerekli veri işlem aşamaları gerçekleştirilmiştir (Tablo 1). Çalışmada kullanılan veri (URL-1 2018), ilgili depremler için Kandilli Rasathanesi Bölgesel Deprem-Tsunami İzleme ve Değerlendirme Merkezi veri tabanından geniş bandlı Aydın (AYDB) istasyonu verisinden oluşmaktadır. Çalışmada, kullanılan tekniğin doğası gereği her bir frekans aralığında normalize edilmiş genliklerin uzaklığa bağlı değişimini temsil eden eğim miktarı ile belirlenmesi, kullanılan depremlerin lokasyon dağılımlarının incelendiğinde, aynı zamanda, ortaya çıkan soğrulma fonksiyonlarının AYDB istasyonunun batısına doğru yaklaşık uzunluğu $100 \mathrm{~km}$ olan bir profili de temsil ettiği söylenebilir.

Tablo 1: Çalışmada kullanılan depremler (Deprem kodu ilgili depreme ait tarih ve saat bilgisini içermektedir)

\begin{tabular}{|c|c|c|c|c|c|c|c|c|c|}
\hline $\begin{array}{c}\begin{array}{c}\text { Deprem } \\
\text { Kodu }\end{array} \\
\end{array}$ & $\begin{array}{c}\text { Enlem } \\
\text { (Derece) }\end{array}$ & $\begin{array}{l}\begin{array}{c}\text { Boylam } \\
\text { (Derece) }\end{array} \\
\end{array}$ & $\begin{array}{c}\text { Derinlik } \\
(\mathbf{k m})\end{array}$ & $\mathbf{M}$ & $\begin{array}{c}\begin{array}{c}\text { Deprem } \\
\text { Kodu }\end{array} \\
\end{array}$ & $\begin{array}{c}\text { Enlem } \\
\text { (Derece) }\end{array}$ & $\begin{array}{l}\text { Boylam } \\
\text { (Derece) }\end{array}$ & $\begin{array}{c}\text { Derinlik } \\
(\mathbf{k m})\end{array}$ & $\mathbf{M}$ \\
\hline 20161120091552 & 38.00 & 27.64 & 2.6 & 2.8 & 20120426065054 & 37.85 & 26.92 & 8.7 & 3.3 \\
\hline 20161024080447 & 37.97 & 27.56 & 5.8 & 3.3 & 20120420015144 & 37.94 & 27.67 & 4.7 & 2.7 \\
\hline 20160606195256 & 37.86 & 27.65 & 5 & 2.9 & 20120318083554 & 37.91 & 27.11 & 7.9 & 3.2 \\
\hline 20160513155438 & 37.85 & 26.69 & 12.9 & 3.2 & 20111007085958 & 37.86 & 27.27 & 5 & 3.2 \\
\hline 20151023182939 & 37.98 & 26.80 & 13 & 4.1 & 20110803175030 & 37.87 & 27.30 & 5.5 & 3.3 \\
\hline 20150712195133 & 37.86 & 27.25 & 1.7 & 3.4 & 20110530114658 & 37.80 & 26.94 & 11.3 & 3.3 \\
\hline 20150712195009 & 37.85 & 27.21 & 10.6 & 3.6 & 20110409235445 & 37.90 & 27.32 & 5 & 3.2 \\
\hline 20150617113252 & 37.87 & 27.24 & 3.3 & 3.4 & 20110305055252 & 37.97 & 27.24 & 5 & 3.2 \\
\hline 20150617061656 & 37.85 & 27.26 & 5 & 3.3 & 20110222152339 & 37.87 & 27.34 & 5 & 3.6 \\
\hline 20150617043217 & 37.89 & 27.22 & 7.6 & 3.2 & 20110218045455 & 37.88 & 27.26 & 2 & 3.3 \\
\hline 20150328020512 & 37.96 & 27.21 & 5.9 & 3.2 & 20110217093248 & 37.92 & 27.36 & 2.9 & 3.2 \\
\hline 20150327014241 & 37.95 & 27.22 & 7.4 & 4 & 20110212011427 & 37.87 & 27.15 & 3.6 & 3.5 \\
\hline 20141012134125 & 37.98 & 27.18 & 11.2 & 3.2 & 20110204231211 & 37.84 & 27.37 & 5 & 3.8 \\
\hline 20140602092717 & 37.87 & 26.95 & 2.7 & 3.7 & 20101216174146 & 37.86 & 27.33 & 6.5 & 3.5 \\
\hline 20130216120333 & 37.88 & 27.13 & 3.7 & 3.2 & 20101213073033 & 37.89 & 27.63 & 9.8 & 2.7 \\
\hline
\end{tabular}


Tablo 1'in Devamı

\begin{tabular}{|c|c|c|c|c|c|c|c|c|c|}
\hline $\begin{array}{c}\text { Deprem } \\
\text { Kodu }\end{array}$ & $\begin{array}{c}\text { Enlem } \\
\text { (Derece) }\end{array}$ & $\begin{array}{c}\text { Boylam } \\
\text { (Derece) }\end{array}$ & $\begin{array}{c}\text { Derinlik } \\
(\mathbf{k m})\end{array}$ & $\mathbf{M}$ & $\begin{array}{c}\text { Deprem } \\
\text { Kodu }\end{array}$ & $\begin{array}{c}\text { Enlem } \\
\text { (Derece) }\end{array}$ & $\begin{array}{c}\text { Boylam } \\
\text { (Derece) }\end{array}$ & $\begin{array}{c}\begin{array}{c}\text { Derinlik } \\
(\mathbf{k m})\end{array} \\
\end{array}$ & $\mathbf{M}$ \\
\hline 20121210094829 & 37.84 & 27.34 & 3 & 3.8 & 20101208215052 & 37.88 & 27.34 & 6.8 & 4 \\
\hline 20120925122034 & 37.88 & 27.63 & 5.4 & 2.7 & 20101121183309 & 37.87 & 26.81 & 6.1 & 3.2 \\
\hline 20120911232146 & 37.87 & 26.67 & 8.4 & 3.2 & 20101119210715 & 37.89 & 27.39 & 5.4 & 3.2 \\
\hline 20120911181916 & 37.87 & 26.68 & 8.9 & 3.2 & 20101119200612 & 37.88 & 27.39 & 5 & 3.2 \\
\hline 20120828150816 & 37.90 & 26.70 & 5 & 3.5 & 20101116113445 & 37.88 & 27.41 & 6.2 & 3.2 \\
\hline 20120828083809 & 37.86 & 26.72 & 5 & 3.3 & 20101114052145 & 37.92 & 27.39 & 5 & 3.9 \\
\hline 20120827214229 & 37.86 & 26.73 & 3.6 & 3.3 & 20101112085417 & 37.91 & 27.37 & 5 & 3.4 \\
\hline 20120827213302 & 37.84 & 26.63 & 3.4 & 3.3 & 20101111200800 & 37.93 & 27.35 & 11.5 & 4.7 \\
\hline 20120827212915 & 37.85 & 26.65 & 4.5 & 3.2 & 20101111194551 & 37.86 & 27.37 & 5.3 & 3.2 \\
\hline 20120827152832 & 37.90 & 26.71 & 5 & 3.2 & 20101111191554 & 37.90 & 27.37 & 5 & 3.5 \\
\hline 20120816011437 & 37.86 & 26.70 & 6.8 & 3.5 & 20101011180357 & 37.94 & 27.36 & 7.7 & 3.2 \\
\hline 20120815221831 & 37.83 & 26.63 & 5 & 3.8 & 20100926205937 & 37.88 & 27.63 & 2.2 & 3.1 \\
\hline 20120815221010 & 37.85 & 26.68 & 5 & 3.6 & 20100812134651 & 37.90 & 26.86 & 5.4 & 3.2 \\
\hline 20120815220329 & 37.86 & 26.67 & 6.8 & 3.4 & 20100811021618 & 37.88 & 26.80 & 5.5 & 3.6 \\
\hline 20120803072610 & 37.82 & 26.66 & 2.1 & 3.4 & 20100808111432 & 37.90 & 26.78 & 7.2 & 3.3 \\
\hline 20120730071353 & 37.87 & 26.67 & 5 & 3.4 & 20100728151415 & 37.87 & 27.44 & 5 & 3.3 \\
\hline 20120730060200 & 37.88 & 26.72 & 9.9 & 3.3 & 20100720195732 & 37.94 & 27.08 & 4.8 & 3.2 \\
\hline 20120618190118 & 37.81 & 27.63 & 10.2 & 2.7 & 20100611201651 & 37.83 & 27.60 & 5 & 2.9 \\
\hline
\end{tabular}
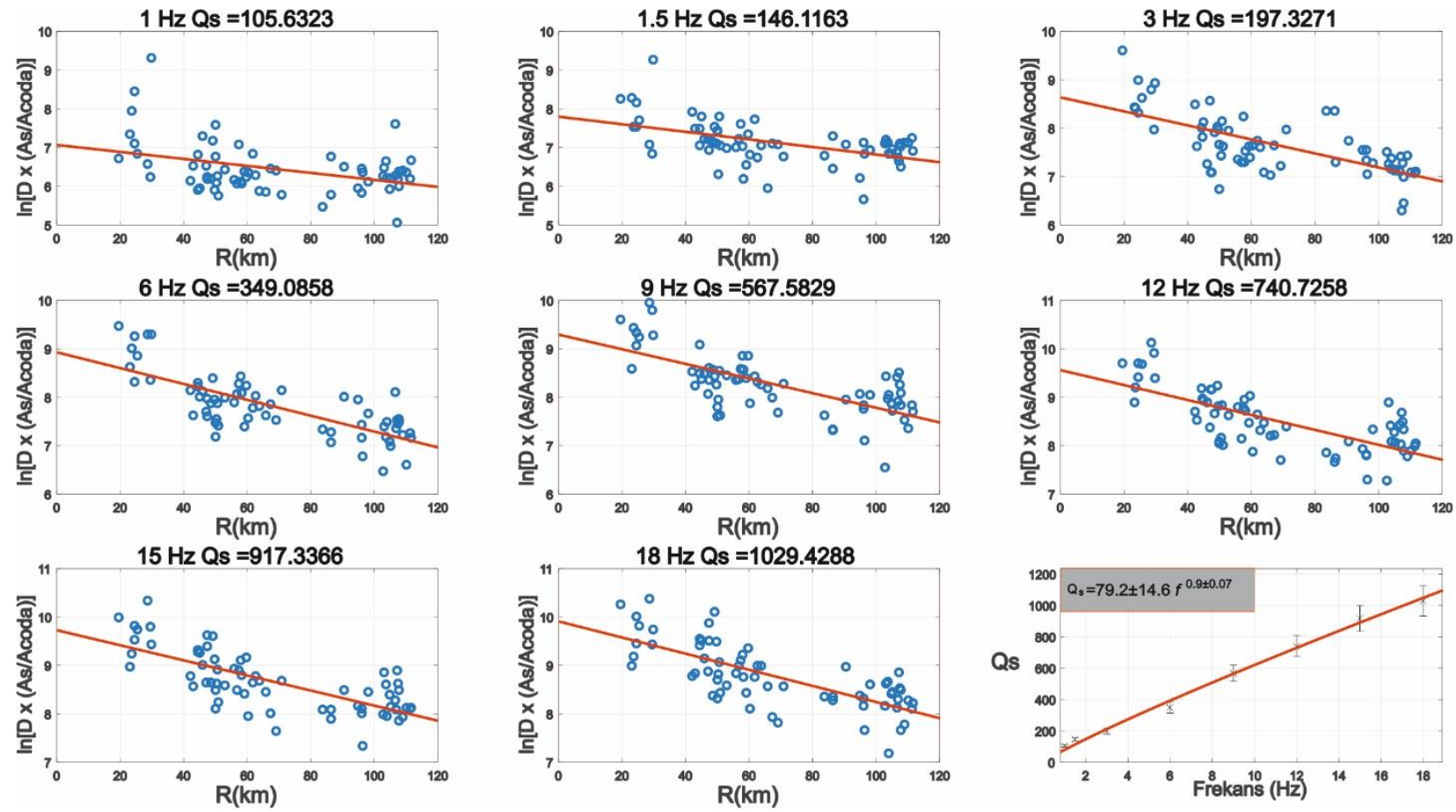

Şekil 3: 1-18 Hz arası merkez frekans değerlerinde, Koda Fazına normalize edilmiş S fazı genliklerinin uzaklığa bağlı değişimi, Qs değerleri ve frekansa bağlı Qs değişim fonksiyonu 

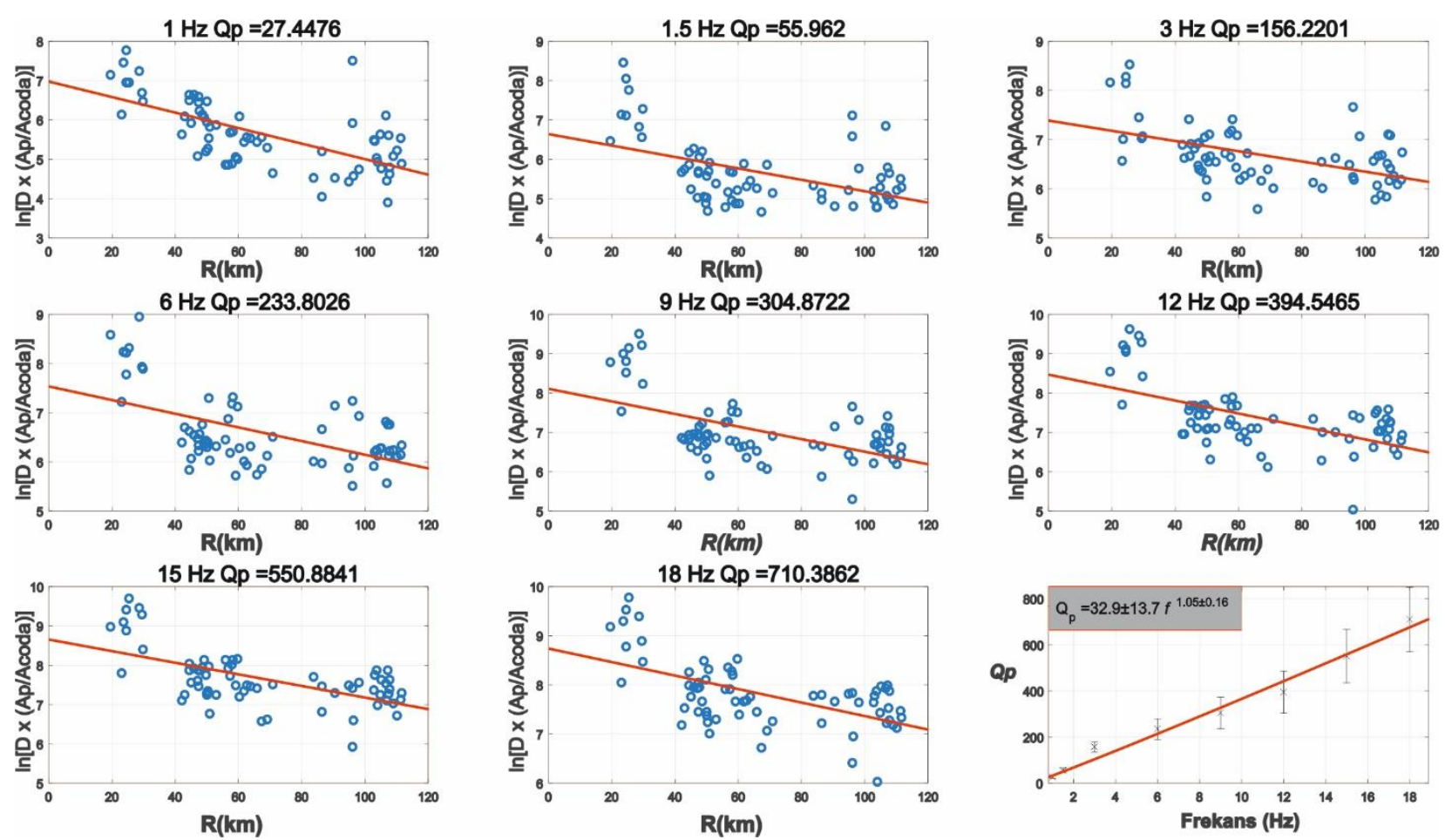

Şekil 4: 1-18 Hz arası merkez frekans değerlerinde, Koda Fazına normalize edilmiş $P$ fazı genliklerinin uzaklığa bağlı değişimi, Qp değerleri ve frekansa bağlı Qp değişim fonksiyonu

\section{Tartışma ve Sonuçlar}

Bu çalışma kapsamında ortaya çıkan sonuçlar, bölgede veya yakın civarında gelecekte olması muhtemel hasar yapıcı büyük depremlerin daha doğru bir şekilde modellenebilmesi ve gerekli deprem tehlike çalışmalarının da daha güvenilir sonuçlar elde edilmesi için gerekli olan temel parametrelerden biri olan soğrulma ilişkilerini ortaya koymaktadır. Büyük Menderes grabeninde farklı sismik fazlar için elde edilen sönüm kalite faktörleri, karmaşık kabuk yapısı ve kabuktaki muhtemel heterojeniteye bağlı düşey değişimlerinin bir sonucu olarak artan uzaklıklarda genlik azalmaları göstermektedir. Bu anlamlı azalım, 66 farklı deprem için AYDB istasyonu verileri kullanılarak $1 \mathrm{~Hz}-18 \mathrm{~Hz}$ arasındaki 8 farklı frekans bandında elde edilen sonuçlarda da gözlenmiştir. İlgili merkez frekanslarda elde edilen bu sönüm kalite faktörünün (Q), frekans bağımlılı̆̆ üstel kuvvet kanunu kullanılarak, fonksiyon tanımlı hale getirilmiştir. Elde edilen sonuçlara göre $\mathrm{S}$ ve $\mathrm{P}$ sismik fazları için sırasıyla, $\mathrm{Q}_{\mathrm{s}}=79.2 \pm 14.6 \mathrm{f}^{0.9 \pm 0.07}$ (Şekil 3) ve $\mathrm{Q}_{\mathrm{p}}=32.9 \pm 13.7 \mathrm{f}^{1.05 \pm 0.16}$ (Şekil 4) fonksiyonları ortaya çıkarılmıştır. Elde edilen parametrik olmayan bu soğrulma fonksiyonları, kabuk yapısındaki düşey ve yanal değişimler nedeniyle farklı mesafe aralıklarında oluşan genlik azalım oranındaki değişiklikleri temsil etmektedir. Bir başka deyişle kabuk yapısının heterojenite miktarı, bu fonksiyonları ve farklı fazların soğrulma değerlerinin birbirleriyle olan oranlarını doğrudan etkilemektedir. Bu oran bölgenin sismik aktivitesi hakkında da önemli bilgiler sağlamakla beraber, çalışma alanının deprem riski kavramı açısından değerlendirme çalışmalarına farklı bir bakış açısı sunmaktadır Dolayısıyla, sönüm kalite faktörünün (Q) gözlemsel değerlerini açıklamak ve olası soğrulma mekanizmalarını ortaya koymak amacıyla, $Q_{S} / Q_{P}$ oranı da çalışma kapsamında hesaplanmıştır. İncelenen frekans aralıklarının tümünde (1-18 Hz) QS / QP> 1 olması, saçılma etkisinin, çalışma alanında cisim dalgalarının artan mesafe ile genlik azalmasını kontrol eden önemli bir zayıflatma mekanizması olduğunun göstergesi olarak ortaya çıkmaktadır (Hough ve Anderson 1988). Saçılma etkisinin bu kadar fazla olması ise bölgedeki yoğun heterojenitenin bir işareti olarak yorumlanabilmektedir. Ayrıca, $\mathrm{Q}=\mathrm{Q}_{0} \mathrm{f}^{\mathrm{n}}$ ilişsisinde $\mathrm{Q}_{0}$ ve frekans ilişkisi (n) parametreleri belirlenmektedir. Eşitlikler incelendiğinde $\mathrm{Q}_{0}$ 'ın her iki dalga fazı için de düşük değerler aldığı ve frekans ilişkisi (n) parametresinin de 1 civarında değiştiği gözlenmektedir. Düşük $\mathrm{Q}_{\mathrm{p}}$ ve $\mathrm{Q}_{\mathrm{s}}$ dünyadaki sismik açıdan aktif alanlara karşsllk gelmektedir (Yoshimoto vd. 1993). Tüm frekans aralıkları incelendiğinde ise bölgede $P$ dalgalarının $S$ dalgalarından daha hızlı sönümlendiği görülmektedir. $1 \mathrm{~Hz}$ 'den büyük frekanslarda $\mathrm{Q}_{\mathrm{S}} / \mathrm{Q}_{\mathrm{P}}$ oranı ortalama $\sim 1.75$ olarak hesaplanmıştır. $\mathrm{Q}_{\mathrm{S}} / \mathrm{Q}_{\mathrm{P}}$ oranının 1'den büyük olması üst kabuktaki yüksek dereceli yanal heterojenite ile açıklanmaktadır (Bianco vd. 1999; Sato ve Fehler 1998). Çalışma alanındaki özellikle graben oluşumunu kuzeyden sınırlayan fay topluluklarının yapısı da bu görüşü desteklemektedir. 
Tablo 2: Literatürdeki farklı çalışma alanlarında ortaya çıkarılmış Qp ve Qs Fonksiyonları

\begin{tabular}{l|l|l|l|l} 
Referans & Çalışma Alanı & Qp Fonksiyonu & Qs Fonksiyonu & Qs/Qp \\
\hline Castro vd. (2008) & $\begin{array}{l}\text { Kuzeydoğu Sonora, } \\
\text { Meksika }\end{array}$ & $\mathrm{Q}_{\mathrm{p}}=20.8 \mathrm{f}^{1.1}$ & $\mathrm{Q}_{\mathrm{s}}=83.8 \mathrm{f}^{0.9}$ & $>1.9$ \\
\hline Yoshimoto vd. (1993) & Kanto, Japonya & $\mathrm{Q}_{\mathrm{p}}=32.25 \mathrm{f}^{0.95}$ & $\mathrm{Q}_{\mathrm{s}}=83.33 \mathrm{f}^{0.73}$ & $>1$ \\
\hline Mahood vd. (2009) & Doğu İran & $\mathrm{Q}_{\mathrm{p}}=40 \pm 4.8 \mathrm{f}^{0.99 \pm 0.04}$ & $\mathrm{Q}_{\mathrm{s}}=52.6 \pm 5.5 \mathrm{f}^{1.02 \pm 0.06}$ & - \\
\hline Padhy (2009) & Bhuj, Hindistan & $\mathrm{Q}_{\mathrm{p}}=19.23 \pm 7.02 \mathrm{f}^{1.1 \pm 0.06}$ & $\mathrm{Q}_{\mathrm{s}}=50 \pm 25 \mathrm{f}^{1.02 \pm 0.04}$ & $>1$ \\
\hline Kumar vd. (2014) & Kinnaur, Himalayalar & $\mathrm{Q}_{\mathrm{p}}=47 \pm 2 \mathrm{f}^{1.04 \pm 0.04}$ & $\mathrm{Q}_{\mathrm{s}}=86 \pm 4 \mathrm{f}^{0.96 \pm 0.03}$ & $1.5-1.9$ \\
\hline Abdel-Fattah (2009) & Cairo, Misır & $\mathrm{Q}_{\mathrm{p}}=52.6 \pm 5.5 \mathrm{f}^{0.8 \pm 0.1}$ & $\mathrm{Q}_{\mathrm{s}}=142.85 \pm 20.4 \mathrm{f}^{0.85 \pm 0.1}$ & 2.6 \\
\hline Pezeshk vd. (2018) & New Madrid Fayı, ABD & $\mathrm{Q}_{\mathrm{p}}=115.8 \pm 1.36 \mathrm{f}^{+0.495 \pm 0.13}$ & $\mathrm{Q}_{\mathrm{s}}=161.34 \pm 1.73 \mathrm{f}^{0.613 \pm 0.067}$ & $>1$ \\
\hline Bu çalışma & $\begin{array}{l}\text { Büyük Menderes Grabeni, } \\
\text { Türkiye }\end{array}$ & $\mathrm{Q}_{\mathrm{p}}=32.9 \pm 13.7 \mathrm{f}^{1.05 \pm 0.16}$ & $\mathrm{Q}_{\mathrm{s}}=79.2 \pm 14.6 \mathrm{f}^{0.9 \pm 0.07}$ & 1.75 \\
\hline
\end{tabular}

Elde edilen ilişki fonksiyonları dünyadaki farklı alanlarda yapılan çalışmalarla karşılaştırılmıştır (Tablo 2). Özellikle sismik açıdan oldukça aktif alanlarda elde edilen sonuçlar ile oldukça yakın ilişki fonksiyonları ve Qs/Qp oranlarının ortaya çıkması çarpıcı bir sonuç olarak ele alınabilir. Özellikle Kuzeydoğu Sonora (Castro vd. 2008), Kanto (Yoshimoto vd, 1993) ve Kinnaur (Kumar vd. 2014) bölgeleri gibi geçmişte büyük deprem etkisine maruz kalmış ve aktivitesini hala koruyan tektonik ortamlarda elde edilen sonuçlar ile yakın sonuçlar elde edilmesi, çalışma alanının ne denli yoğun bir sismik etkinliğe sahip olduğunun ve olacağının bir göstergesi olmaktadır.

\section{Teşekkür}

Makalenin son haline gelmesindeki değerli katkılarından dolayı Doç. Dr. Halil AKINCI ve ismi belirtilmeyen üç hakeme teşekkürlerimizi sunarız. Şekil 1'in oluşturulmasında GMT (Wessel ve Smith 1995) yazılımı kullanılmıştır.

\section{Kaynaklar}

Abdel-Fattah A.K., (2009), Attenuation of body waves in the crust beneath the vicinity of Cairo Metropolitan area (Egypt) using coda normalization method, Geophysical Journal International, 176,126-134.

Altinok Y., Alpar B., Özer N., Aykurt H., (2011), Revision of the tsunami catalogue affecting Turkish coasts and surrounding regions, Natural Hazards Earth and System Sciences, 11, 273-291.

Aki K., (1969), Analysis of seismic coda of local earthquakes as scattered waves, Journal of Geophysical Research, 74, 615-631.

Aki K., (1980), Attenuation of shear-waves in the lithosphere for frequencies from 0.05 to $25 \mathrm{~Hz}$, Physics of the Earth and Planetary Interiors 21, 50-60.

Ambraseys N.N., (1988), Temporary seismic quiescence: SE Turkey, Geophysical Journal, 96, 311-331.

Ambraseys N.N., Finkel C.F., (1995), The Seismicity of Turkey and Adjacent Areas a Historical Review, 1500-1800, Muhittin Eren Yayınc1lık, İstanbul, Türkiye, 240ss.

Arpat E., Bingöl E., (1969), The rift system of the Western Turkey, Bulletin of the Mineral Research and Exploration Institute of Turkey, 73, 1-9.

Barka A., Reilinger R., (1997), Active tectonics of the Eastern Mediterranean region: deduced from GPS, neotectonic and seismicity data. Annali di Geofisica, 40, 587-610.

Bianco F., Castellano M., Del Pezzo E., Ibañez J.M., (1999), Attenuation of short-period seismic waves at Mt. Vesuvius, Italy. Geophysical Journal International, 138, 67-76.

Bozkurt E., (2001), Neotectonics of Turkey-a synthesis. Geodinamica Acta, 14, 3-30.

Bozkurt E., (2003), Origin of NE-trending basins in western Turkey, Geodinamica Acta, 16, 61-81.

Castro R.R., Condori C., Romero O., Jacques C., Suter M., (2008), Seismic attenuation in northeastern Sonora, Mexico, Bulletin of the Seismological Society of America, 98, 722-732.

Dewey J.F., Şengör A.M.C., (1979), Aegean and surrounding regions: Complex multiplate and con tinuum tectonics in a convergent zone, Geological Society of America Bulletin, 90, 84-92.

Emre Ö., Duman T.Y., Duman Ş., Özalp S., (2012), Türkiye diri fay haritası, Maden Tetkik ve Arama Yayınları, Ankara, Türkiye.

Görür N., Şengör A.M.C., Sakınç M., Tüysüz O., Akkök R., Yiğitbaş E., Oktay F.Y., Barka A.A., Sarıca N., Ecevitoğlu B., Demirbağ E., Ersoy Ş., Algan O., Güneysu C., Aykol A., (1995), Rift formation in the Gökova region, southwest Anatolia: implications for the opening of the Aegean Sea, Geological Magazine, 132, 637-650.

Guidoboni E., Comastri A., Triana G., (1994), Catalogue of Ancient Earthquakes in the Mediterranean Area up to the10th Century, Istituto Nazionale di Geofisica, Rome, Italy, 504ss.

Hancock P.L., Barka A.A., (1987), Kinematic indicators on active normal faults in western Turkey, Journal of Structral Geolology, 9(3), 415-430.

Herrmann R.B., Kijko A., (1983), Modelling some empirical vertical component Lg relations, Bulletin of the Seismological Society of America, 73, 157- 171.

Hough S.E., Anderson J.G., (1988), High frequency spectra observed at Anza, California: Implications for Q structure, Bulletin of the Seismological Society of America, 78, 672-691.

Jackson J., McKenzie D., (1988), The relationship between plate motions and seismic tremors, and the rates of active deformation in the Mediterranean and Middle East, Geophysical Journal of the Royal Astronomical Society, 93, 45-73. 
Koçyiğit A., Yusufoğlu H., Bozkurt E., (1999), Evidence from the Gediz graben for episodic twostage extension in western Turkey, Journal of Geological Society, 156, 605-616.

Koçyiğit A., (2000), Güneybatı Türkiye'nin depremselliği, Batı Anadolu'nun depremselliği sempozyumu (BAD SEM2000), İzmir, Türkiye, ss.30-38.

Kumar N., Mate S., Mukhopadhyay S., (2014), Estimation of $Q p$ and $Q$ s of Kinnaur Himalaya, Journal of Seismology, 18, 47-59.

Ma'hood M., Hamzehloo H., Doloei G.J., (2009), Attenuation of high frequency $P$ and $S$ waves in the crust of the East Central Iran, Geophysical Journal International, 179, 1669-1678.

McClusky S., Balassanian S., Barka A., Demir C., Ergintav S., Georgiev I., Gurkan O., Hamburger M., Hurst K., Kahle H., Kastens K., Kekelidze G., King R., Kotzev V., Lenk O., Mahmoud S., Mishin A., Nadariya M., Ouzounis A., Paradissis D., Peter Y., Prilepin M., Reilinger R., Sanli I., Seeger H., Tealeb A., Toksöz M.., Veis G., (2000), Global positioning system constraints on plate kinematics and dynamics in the eastern Mediterranean and Caucasus, Journal of Geophysical Research, 105, 5695-5719.

Özer Ç., Gök E., Polat O., (2017), Ege Bölgesi graben sistemlerinin kabuk hız yapısı. 4. Uluslararası Deprem Mühendisliği ve Sismoloji Konferans1, Eskişehir, Türkiye, ss.1-8.

Padhy S., (2009), Characteristics of body wave attenuations in the Bhuj crust, Bulletin of the Seismological Society of America, 99, 3300-3313.

Pezeshk S., Sedaghati F., Nazemi N., (2018), Near-source attenuation of high-frequency body waves beneath the New Madrid Seismic Zone, Journal of Seismology, 22, 455-470.

Reilinger R., McClusky S., Oral B., King R., Toksoz M, Barka A., Kinik L., Lenk O., Sanli I., (1997), Global Positioning System measurements of present-day crustal movements in the Arabia-Africa-Eurasia plate collision zone, Journal of Geophysical Research, 102, 9983-9999.

Sato H., (1977), Energy propagation including scattering effects: single isotropic scattering. Journal of Physics of the Earth, 25, 2741.

Sato H., Fehler M.C., (1998), Seismic Wave Propagation and Scattering in the Heterogeneous Earth, Springer-Verlag, Berlin, Germany, 308ss.

Sato H., Matsumura S., (1980), Three-dimensional analysis of scattered P waves on the basis of the PP single isotropic scattering model, Journal of Physics of the Earth, 28, 521-530.

Seyitoğlu G., Scott B.C., (1991), Late Cenozoic crustal extension and basin formation in west Turkey, Geological Magazine, 128, 155166.

Şengör A.M.C., Y1lmaz Y., (1981), Tethyan evolution of Turkey: A plate tectonic approach, Tectonophysics, 75,181-241.

Şengör A.M.C., Görür N., Şaroğlu F., (1985), Strike-slip faulting and related basin formation in zones of tectonic escape: Turkey as a case study, Strike-slip Deformation, Basin Formation, and Sedimentation, Society of Economic Paleontologists and Mineralogists, Specical Publications (in honor of J.C. Crowell), 37, 227-264.

Şengör A.M.C., (1987), Cross-faults and differential stretching of hanging walls in regions of lowangle normal faulting; Examples from western Turkey, Continental Extensional Tectonics. (Eds. M. P. Coward, J. F. Dewey and P. L. Hancock), Geological Society Publications, 28, 575-589.

Taymaz T., Jackson J., McKenzie D., (1991), Active tectonics of the north and central Aegean Sea. Geophysical Journal International, 106, 433-490.

URL-1, (2018), Boğaziçi Üniversitesi Kandilli Rasathanesi ve Deprem Araştırma Enstitüsü Bölgesel Deprem-Tsunami İzleme ve Değerlendirme Merkezi, http://www.koeri.boun.edu.tr/sismo/2/data-request/, (Erişim 15 Şubat 2018).

Wessel P., Smith, W.H.F., (1995), New version of the Generic Mapping Tools, Eos Transactions, 76, 329-329.

Yoshimoto K., Sato H., Ohtake M., (1993), Frequency-dependent attenuation of $P$ and $S$ waves in the Kanto area, Japan, based on the coda normalization method, Geophysical Journal International, 114, 165-174. 